Journal of the Electrochemical Society, 1989, Volume 136, Issue 1, Pages 42-46.

ISSN: 0013-4651

DOI: $10.1149 / 1.2096611$

http://www.electrochem.org

http://scitation.aip.org/getpdf/servlet/GetPDFServlet?filetype=pdf\&id=JESOAN000136000001000042000001\&idty pe $=$ cvips \&prog=normal

(C) The Electrochemical Society, Inc.1989. All rights reserved. Except as provided under U.S. copyright law, this work may not be reproduced, resold, distributed, or modified without the express permission of The Electrochemical Society (ECS). The archival version of this work was published in Journal of the Electrochemical Society, 1989, Volume 136, Issue 1, Pages 42-46.

\title{
Corrosion of Thin Film Magnetic Disk: Galvanic Effects of the Carbon Overcoat
}

\author{
V. Brusic,* M. Russak, R. Schad, G. Frankel, A. Selius, and D. DiMilia \\ IBM Thomas J. Watson Research Center, Yorktown Heights, New York. \\ D. Edmonson \\ IBM, SPD, Rochester, Minnesota. \\ * Electrochemical Society Active Member.
}

\begin{abstract}
Thin film magnetic disks are usually coated with a layer of carbon or silica to improve wear properties, enhance flyability, and reduce environmental degradation of the underlying metal layers. In this paper we investigated the effect of dc and RF sputter deposited carbon overcoats on the corrosion behavior of the magnetic layers using electrochemical techniques and a corrosive gas chamber. Corrosion test samples were characterized by optical microscopy, ellipsometry, scanning electron microscopy (SEM), and scanning Auger spectroscopy (SAM) in order to establish the mechanism of corrosion. Corrosion of the magnetic layer was found to be galvanically coupled to the carbon overcoat and influenced by several disk processing parameters.
\end{abstract}

A functional thin film disk has to have good magnetic performance, wear resistance, and long term stability. As the demand for storage capacity increases, the selection of suitable materials relies more on their magnetic properties and less on their chemical stability. Co alloys and $\mathrm{TbFe}$ metal films, which are coming into use for high density magnetic and magneto-optic storage, respectively, have significantly lower chemical stability than the previously used magnetic iron oxide particles.

Thin magnetic films of Co alloys are typically coated by a layer of carbon or $\mathrm{SiO}_{2}$ up to $50 \mathrm{~nm}$ thick to provide the needed wear resistance. If this layer were porefree, it would also provide chemical stability. In reality, films are not perfect and the environment to which they are exposed is not inert. Not only can corrosion occur through imperfections in an overlayer, but it will be enhanced by galvanic interaction if the overlayer is electrochemically active and more noble in potential. One might expect that this is the case with carbon-coated Co alloys. Recently, Novotny et al. (1) have emphasized the galvanic activity of the carbon overcoat. Other investigators, however, have found that carbon decreases the corrosion rate of similar materials by slowing down the lateral growth of corrosion products (2).

The purpose of this work is threefold:

1. To define the principal corrosion mechanism in thin film disks, in particular the role of carbon in the corrosion of CoP. 
2. To evaluate ways to minimize disk corrosion.

3. To develop and utilize experimental techniques which are most suitable for the evaluation of thin film behavior.

Working with structures of $100 \mathrm{~nm}$ or less presents special experimental challenges. The choice of surface preparation techniques, passivation treatments, and test methods are all limited by the thickness of the specimens. Furthermore, the layer beneath the magnetic layer may play a role by influencing the structure of the magnetic layer or altering the electrochemistry if this sublayer is also exposed through defects. There are, however, advantages in working with thin films and thin film structures. For example, vacuum deposition techniques provide unique ways of tailoring thin film properties through a judicious choice of both materials and deposition parameters.

\section{Experimental}

Samples.-The thin film disk structure $\mathrm{AlMg} / \mathrm{NiP} / \mathrm{CoP} / \mathrm{C}$ was studied. The $\mathrm{Ni}_{81} \mathrm{P}_{19}$ and $\mathrm{Co}_{92} \mathrm{P}_{8}$ layers were electrolessly plated, and the $\mathrm{C}$ layer was $\mathrm{dc}$ or $\mathrm{RF}$ magnetron sputter deposited from a pyrolytic graphite target in argon under carefully controlled conditions. Also studied were E-beam deposited $\mathrm{Co}, \mathrm{CoCr}, \mathrm{CoTi}$, and $\mathrm{CoNi}$ films or $\mathrm{NiP}$ or $\mathrm{Si} / \mathrm{SiO}_{2}$ substrates and 99.997\% pure Co foil from Johnson Matthey Chemicals Limited. Some of the Co and CoP films were covered by a thin dielectric layer of a dc sputtered glassy oxide and evaluated as such or further over-coated with a thin carbon layer. Carbon films were also deposited in the range of 25$60 \mathrm{~nm}$ on a nonconducting substrate in order to measure electrical resistivity and evaluate the electrochemical behavior of carbon alone.

Procedure.-Electrochemical tests.-Samples with no surface pretreatment were exposed to an electrolyte, and their behavior was monitored by electrochemical techniques using an EG\&G Model 350A corrosion console. Two types of experimental cells were used. One is an airtight cell made of Kel-F and equipped with quartz windows to allow for simultaneous ellipsometric measurements. Most of the experiments, however, were conducted in a much simpler miniature cell designed to mimic the conditions of atmospheric corrosion while preserving the advantages of a three-electrode cell. The schematic of the cell is given in Fig. 1. It consists of the sample (working electrode) masked with plating tape to expose only a $0.32 \mathrm{~cm}^{2}$ area, Pt mesh (counterelectrode), and a mercurous sulfate electrode (reference electrode), with a filter paper disk separating each electrode. A $20 \mu \mathrm{l}$ droplet of electrolyte was used. Due to small distances between the electrodes, the ohmic resistance in the cell is relatively small even with electrolytes such as DI and triple distilled water. As the ohmic resistance of the latter is only about $800 \Omega$ in the first seconds of measurement, insignificant errors in the evaluation of corrosion rates are introduced. Since mild electrolytes such as water may be used and the thinness of the electrolyte brings a lot of oxygen to the surface, this setup is very close to the conditions of atmospheric corrosion.

The procedure was to monitor the corrosion potential on exposure for about $15 \mathrm{~min}$ and periodically measure the polarization resistance by scanning at a rate of $1 \mathrm{mV} / \mathrm{s}$ over $\pm 15 \mathrm{mV}$ from the corrosion potential. The corrosion rate was routinely calculated with the program 


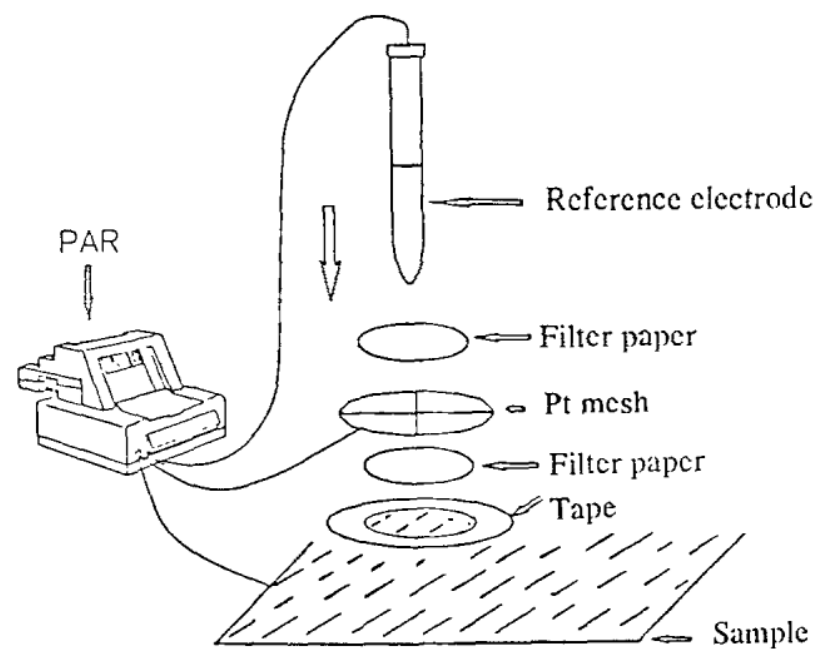

Fig. 1. Schematic of the "droplet" cell for corrosion measurements

provided by the EG\&G system assuming anodic and cathodic Tafel slopes of 0.10 and 0.12 V/dec, respectively. The use of the "reasonable estimates" instead of "true values" causes an error in the calculation of the corrosion rate. The maximum possible error, however, is limited to a factor of 2.2 (3) and in this work stayed below 1.5. The potentiodynamic polarization curve was then measured at a rate of $1 \mathrm{mV} / \mathrm{s}$ from $0.25 \mathrm{~V}$ cathodic of the corrosion potential. Polarization resistance measurements in a mild electrolyte, such as water, are very suitable for the study of thin films. In contrast, much or all of a film can be dissolved during potentiodynamic sweeps, but such tests are quite informative as they provide an assessment of the ability of a metal to passivate and of possible galvanic exposure. Some of the results were obtained with the Model 378 electrochemical impedance system by EG\&G. All of the potentials are expressed in volts against the mercurous sulfate electrode.

Accelerated corrosion chambers. - Samples were also exposed to clean or contaminated air with varying temperature and humidity $(\mathrm{T} / \mathrm{H})$ in glass chambers produced by Interfact Associates, Limited. Most of these tests were conducted in an atmosphere of air with $70 \% \mathrm{RH}$ and $10 \mathrm{ppb}$ of $\mathrm{Cl}_{2}$ at $25^{\circ} \mathrm{C}$. An exposure of $24 \mathrm{~h}$ to this environment was primarily used as a technique for pore decoration in the carbon-covered disk structure, similar to the technique reported by Abbott (4). Quantitative pore counts were made from SEM photographs taken at 1200×. Samples were also characterized by optical microscopy, ellipsometry, and scanning Auger spectroscopy.

\section{Results and Discussion}

$\mathrm{Co}$ and $\mathrm{CoP}$.-Electrochemical tests show that $\mathrm{CoP}$ readily dissolves in water and slightly acidic electrolytes with an average corrosion rate of $3 \times 10^{-6} \mathrm{~A} / \mathrm{cm}^{2}$ or $0.06 \mathrm{~nm} / \mathrm{min}$. This rate decreases slightly over the first few minutes and then is quite constant with time (Fig. 2). "Steady-state" values are listed in Table I. The anodic Tafel slope is low, 35-60 mV/decade, increasing only at $p \mathrm{H}$ 's above 9. In contrast, the cathodic Tafel slope is high, from about 120 $\mathrm{mV} / \mathrm{dec}$ up to several hundred $\mathrm{mV} / \mathrm{dec}$, throughout the evaluated $\mathrm{pH}$ range from 3 to 11 . Typical potentiodynamic polarization curves, obtained in DI water $(p \mathrm{H} 7.2)$ and in $\mathrm{NaOH} / \mathrm{Na}_{2} \mathrm{~B}_{4} 0_{7}(\mathrm{pH}$ 11.0), are given in Fig. 3 as examples. The cathodic reaction, in most cases, proceeds with mixed 
kinetics, with both hydrogen and oxygen reduction playing a role. In DI water oxygen reduction is a predominant cathodic reaction proceeding with a diffusion-limited rate. The value of the diffusion-limited current is about $10^{-5} \mathrm{~A} / \mathrm{cm}^{2}$ (Fig. 3), i.e., of the order expected for the oxygen diffusion in an unstirred electrolyte. The corresponding anodic process has well-defined Tafel region, with an initial slope of $43 \mathrm{mV} / \mathrm{dec}$ changing at higher potentials to even lower value (Fig. 3). The observed reversal of the current-potential slope at the current value of about $10^{-3} \mathrm{~A} / \mathrm{cm}^{2}$ is not a sign of passivation, but a consequence of the catastrophic dissolution of the thin film. At

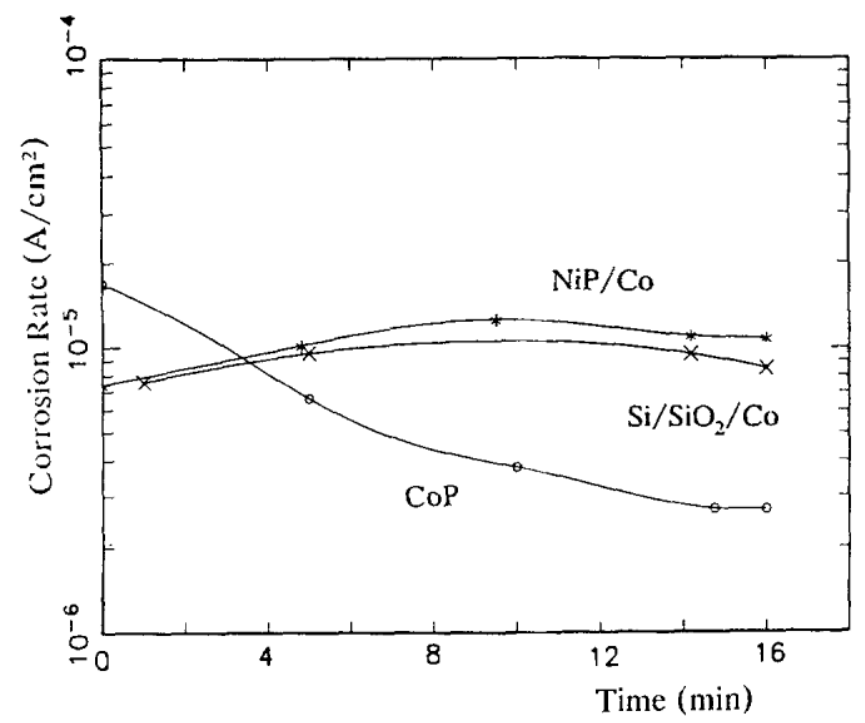

Fig. 2. Variation of corrosion rate with time measured in $\mathrm{DI}$ water on $\mathrm{CoP}, \mathrm{NiP} / \mathrm{Co}$, and $\mathrm{Si} / \mathrm{SiO}_{2} / \mathrm{Co}$ samples.

higher $p \mathrm{H}$ 's the anodic currents are considerably lower, and the Tafel region is replaced by a current-potential relationship normally observed on passive electrodes (Fig. 3). Experiments have shown that the basic reactions in the "droplet cell" are similar to those measured in a large three-electrode cell with an unstirred bulk electrolyte saturated with air, as shown in Fig. 4 for Co-foil in $\mathrm{NaOH} / \mathrm{Na}_{2} \mathrm{~B}_{4} \mathrm{O}_{7}, p \mathrm{H} 11$. Also, it is interesting to note that the Tafel slopes obtained in the "droplet cell" both on $\mathrm{Co}$ and $\mathrm{CoP}$ are similar to the values reported for $\mathrm{Fe}$ (5), $\mathrm{Ni}$ (6), and $\mathrm{Co}$ $(7,8)$ in neutral and acidic solutions and for Fe in slightly alkaline solutions $(9)$, all measured in bulk electrolytes. This suggests that the processes determining the anodic portion of $V \log I$ curve for cobalt are similar to those evaluated in detail for iron (9), i.e.

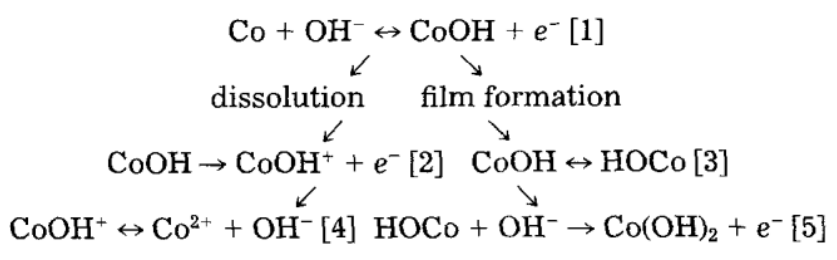

In the absence of oxide formation Eq. [2] is the rate-determining step resulting in the low Tafel 
slope observed. When film formation is kinetically possible, Eq. [5] is the rate-determining step. The value of the corrosion potential for $\mathrm{CoP}$ in neutral electrolytes $(p \mathrm{H} 6$ and 7$)$ is about -0.84 which is just in the potential range where the oxide formation is possible (10). It is also of interest to know if the air-formed oxide dissolves on immersion in the electrolyte or

Table 1. Variation of the steady-state corrosion potential and rate on CoP and Co films as a function of substrate, dielectric, and carbon coating

\begin{tabular}{lcc}
\hline Material & $\begin{array}{c}V_{\text {corr }} \\
\text { (V vs. MSE) }\end{array}$ & $\begin{array}{c}I_{\text {corr }} \\
\left(\mathrm{A} / \mathrm{cm}^{2}\right)\end{array}$ \\
\hline $\mathrm{AlMg} / \mathrm{NiP} / \mathrm{CoP}$ & -0.84 & $2.7 \times 10^{-6}$ \\
$\mathrm{AlMg} / \mathrm{NiP} / \mathrm{CoP} / \mathrm{C}$ & -0.78 & $2.3 \times 10^{-6}$ \\
$\mathrm{AlMg} / \mathrm{NiP} / \mathrm{CoP} / \mathrm{C} \mathrm{RF}^{*}$ & -0.80 & $6.9 \times 10^{-6}$ \\
$\mathrm{AlMg} / \mathrm{NiP} / \mathrm{CoP} / \mathrm{D}^{* *}$ & -0.83 & $1.5 \times 10^{-6}$ \\
$\mathrm{AlMg} / \mathrm{NiP} / \mathrm{CoP} / \mathrm{D} / \mathrm{C}$ & -0.83 & $1.9 \times 10^{-6}$ \\
$\mathrm{AlMg} / \mathrm{NiP} / \mathrm{Co}$ & -0.87 & $1.1 \times 10^{-5}$ \\
$\mathrm{AlMg} / \mathrm{NiP} / \mathrm{Co} / \mathrm{C}$ & -0.80 & $2.7 \times 10^{-6}$ \\
$\mathrm{AlMg} / \mathrm{NiP} / \mathrm{Co} / \mathrm{D}$ & -0.83 & $1.6 \times 10^{-6}$ \\
$\mathrm{AlMg} / \mathrm{NiP} / \mathrm{Co} / \mathrm{D} / \mathrm{C}$ & -0.80 & $1.7 \times 10^{-6}$ \\
$\mathrm{Si} / \mathrm{SiO} / / \mathrm{Co}$ & -0.87 & $9.5 \times 10^{-6}$ \\
$\mathrm{Si} / \mathrm{SiO} / \mathrm{Co} / \mathrm{C}$ & -0.69 & $2.1 \times 10^{-7}$ \\
$\mathrm{Si} / \mathrm{SiO} / \mathrm{Co} / \mathrm{D}$ & -0.86 & $2.0 \times 10^{-8}$ \\
$\mathrm{Si} / \mathrm{SiO} / \mathrm{Co} / \mathrm{D} / \mathrm{C}$ & -0.83 & $2.0 \times 10^{-8}$ \\
\hline
\end{tabular}

*RF sputtered carbon, all other carbon films are dc sputtered. **D stands for a dielectric, $20 \mathrm{~nm}$ thick, of glassy oxides.

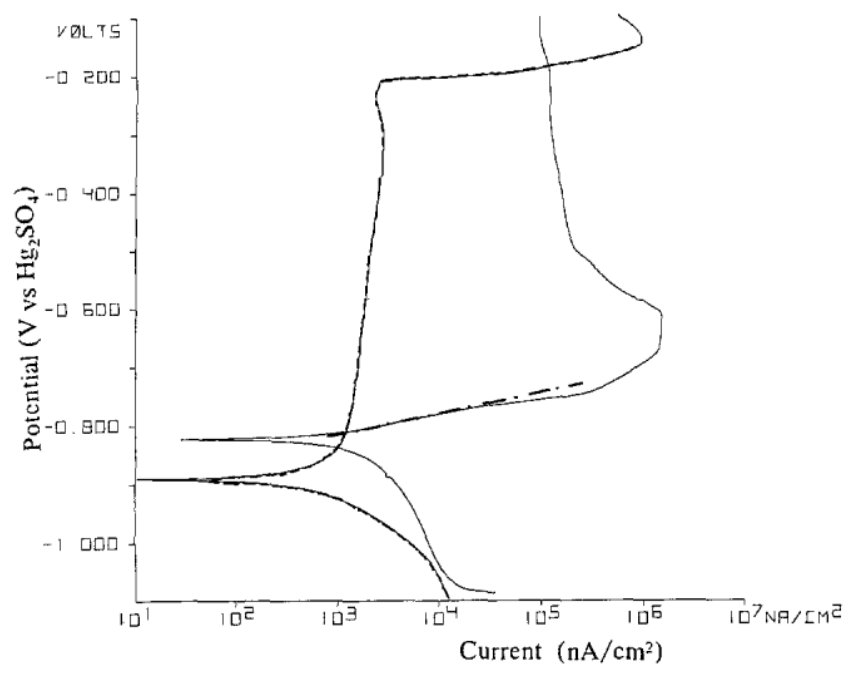

Fig. 3. Potentiodynamic polarization curve on CoP measured in a droplet of Dl water (solid line) and of $\mathrm{NaOH} / \mathrm{Na}_{2} \mathrm{~B}_{4} \mathrm{0}_{7}, \mathrm{pH} 11$ (dashed line). The dash-dot line gives an indication of the Tafel region.

if it protects $\mathrm{Co}$ against further corrosion. In situ ellipsometric measurements made in $0.1 \mathrm{~N}$ $\mathrm{Na}_{2} \mathrm{SO}_{4}$ using a thin film Co sample deposited on a $\mathrm{Si} / \mathrm{SiO}_{2}$ wafer have determined that the airformed oxide disappears from the surface, but the process is slow. In the first 4 min at the opencircuit potential ellipsometric parameter $\Delta$ increases gradually by about $1^{\circ}$. This can be interpreted as a removal of $2-3 \AA$ of the film. The majority of the oxide is removed by a forceful 
reduction at $-1.2 \mathrm{~V}$. At a $p \mathrm{H}$ above 9 , at the open-circuit potential, ellipsometry detects a growth of a very thin new oxide, which is apparently responsible for a decrease of the corrosion rate and an appearance of "passive" range in the V log $I$ curve (Fig. 3). This oxide is stable only while the cobalt is in an alkaline solution. Passivation in alkaline solution, followed by a test in a neutral or acidic environment $(p \mathrm{H} \mathrm{3-6)}$ is short-lived. As this is the $p \mathrm{H}$ range of interest for atmospheric corrosion, we conclude that the corrosion of Co is not inhibited by self-passivation.

Although CoP, Co films, and Co foil samples show similar corrosion behavior [low anodic Tafel slopes, lack of self-passivation (Fig. 3 and 5)] the corrosion rate on CoP initially decreases with time and levels off to a value typically lower than on Co alone (Fig. 2). This effect is most likely not due to an oxide. Our earlier data on NiB and NiP (11) show that phosphorus and boron tend to decrease the passivating ability of a metal and speed up the removal of the air-formed surface oxide on immersion. And yet in all cases the corrosion rate of

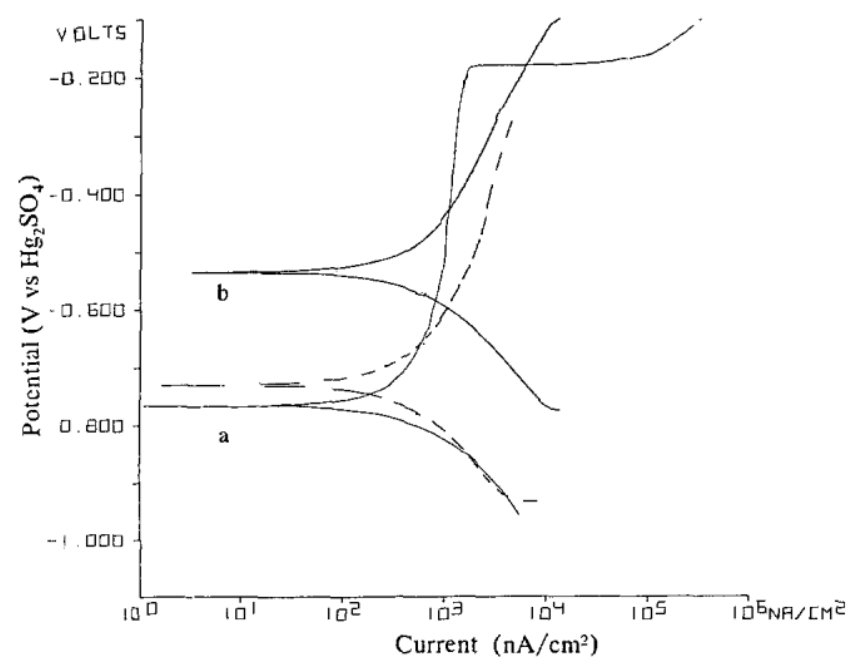

Fig. 4. Potentiodynamic polarization curves on $\mathrm{Co}$ foil in $\mathrm{NaOH} ; \mathrm{Na}_{2} \mathrm{~B}_{2} \mathrm{O}_{7}$ in a droplet cell (dashed line) and in a conventional cell (a) with electrolyte open to air and (b) electrolyte stirred by $\mathrm{O}_{2}$ bubbling. 


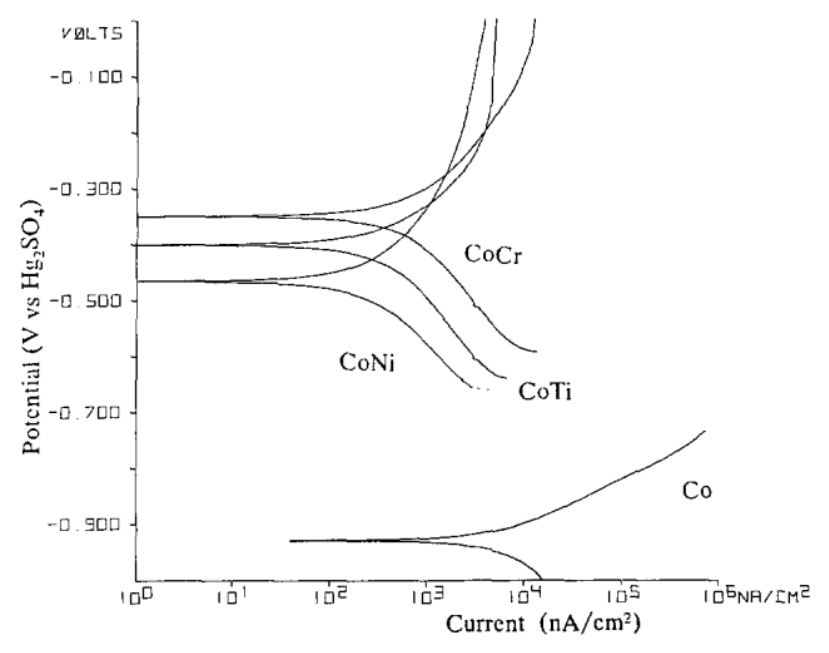

Fig. 5. Potentiodynamic polarization curve on Co, Co-18\% Cr, Co-18\% Ti, and Co-50\% Ni alloys in DI water.

$\mathrm{P}$ (or B) containing films is lower than that of "pure" metallic layers. The explanation for this observation could be due to a reaction of $\mathrm{P}$ with the electrolyte in a similar fashion to that reported recently by Diegle et al. (12) for NiP in acidic solutions. They found that the surface of NiP exposed to acidic solutions contains $\mathrm{H}_{2} \mathrm{PO}_{2}{ }^{-}$While we could not support this notion with ellipsometry (which is not unexpected if the film has an index of refraction close to that of water), such a layer is plausible and could be responsible for the observed diminishing of the corrosion rate of $\mathrm{CoP}$ with time to a value lower than $\mathrm{Co}$, similar to observations on $\mathrm{NiP}$ (12). In contrast to $\mathrm{Co}$ and $\mathrm{CoP}, \mathrm{Co}$ alloys with $\mathrm{Cr}$, $\mathrm{Ti}$, and $\mathrm{Ni}$ dissolve from an oxide covered, passive surface (Fig. 5).

Influence of carbon overcoats on CoP corrosion.-If the carbon were fully covering the magnetic layer, the corrosion potential and the corrosion rate measured on the layered structures should be similar to the results obtained on the carbon alone. This, however, is not observed.

Four-point probe measurements on thin carbon films deposited on a dielectric substrate show that typical RF and de sputtered layers can be conductive, with resistance value of $0.5-2 \Omega-\mathrm{cm}$. Such films, evaluated by electrochemical tests in a droplet of water, show fairly noble and stable open-circuit potentials of -0.18 to $-0.23 \mathrm{~V}$, and display good catalytic activity for oxygen and hydrogen reduction (Fig. 6). Electrochemical data on carbon-covered $\mathrm{AlMg} / \mathrm{NiP} / \mathrm{CoP}$, $\mathrm{AlMg} / \mathrm{NiP} / \mathrm{Co}$, and $\mathrm{Si} / \mathrm{Si}_{2} / \mathrm{Co}$, show clear differences between the three types of samples (Table I) and bear no resemblance to the behavior of the carbon. While all of them have a higher corrosion potential than their un-coated parallels, the potential is only $40-80 \mathrm{mV}$ higher for the $\mathrm{NiP}$ substrate and more than $150 \mathrm{mV}$ for $\mathrm{Si} / \mathrm{SiO}_{2}$ samples. The average corrosion rate is also a 


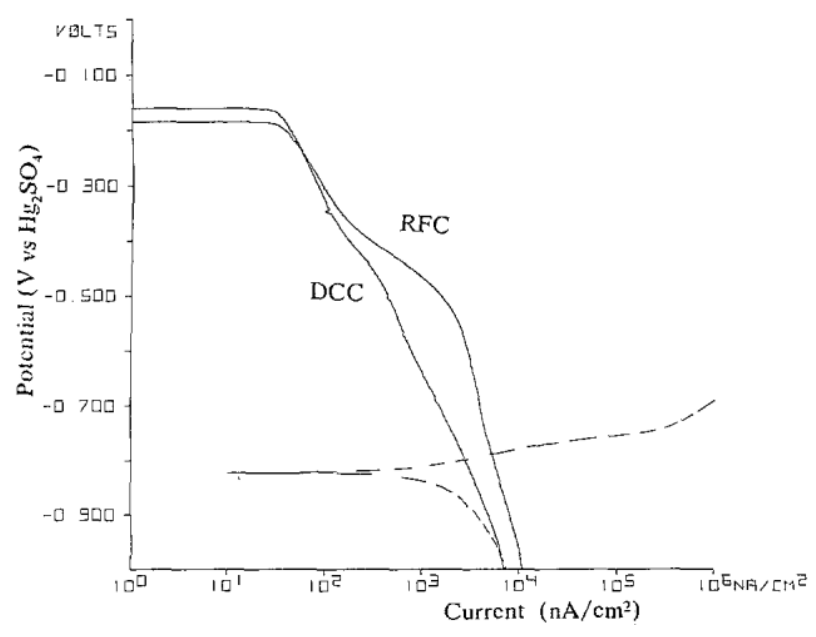

Fig. 6. Cathodic potentiodynamic polarization curves on RF and de sputtered carbon (solid line) and anodic curve on CoP (dashed line).

function of the substrate and significantly lower only on Si. Moreover, some CoP/C samples show higher dissolution than measured on uncoated CoP. This can only be explained by a galvanic interaction of the carbon with the underlying Co or CoP. Apparently the type of substrate, or the roughness of the substrate, determines the metal/C area ratio, i.e., the extent of the galvanic interaction.

Two of the three conditions needed for this system to act as a short-circuit battery (i.e., for galvanic corrosion to occur) are easily illustrated. As evidenced by the potentio-dynamic polarization curves obtained on dc carbon and $\mathrm{CoP}$, the two are electrochemically dissimilar and active materials, fulfilling the first condition. The difference of the open-circuit potentials is more than $0.5 \mathrm{~V}$. Moreover, the very small anodic Tafel slope observed for CoP indicates that even a small rise of the potential, e.g., $40 \mathrm{mV}$, would increase the local dissolution rate by an order of magnitude. Carbon and $\mathrm{CoP}$ are in electrical contact, the second condition, given the layer structure of the thin film disk and knowing that carbon is conductive. The third condition, the necessity for them to be exposed to the same corrosive environment, is not obvious, but depends on the porosity and integrity of the carbon layer.

Judging from the potential alone on carbon and carbon-coated $\mathrm{CoP}$ one can conclude that galvanic attack is possible but the extent to which it will occur depends on all of the factors determining the kinetics of numerous reactions participating in the corrosion process as well as the area of each material capable of reacting. It is possible to estimate the area ratio by adjusting the positions of the cathodic portion of the polarization curve for carbon and the anodic polarization curve for the bare magnetic alloys until the intercept of the curve equals the corrosion potential measured on the carbon-coated structure. The area ratio of the carbon and still "visible" magnetic film is about $14: 1$ on the $\mathrm{AlMg} / \mathrm{NiP} / \mathrm{CoP}$ substrate and about 1000:1 on the smooth $\mathrm{Si} / \mathrm{SiO}_{2} / \mathrm{Co}$. Thus the projected coverage by the carbon is only about $93 \%$ on the actual disk substrate, and better than $99.9 \%$ in the case of $\mathrm{Si}_{/} / \mathrm{SiO}_{2} / \mathrm{Co}$. However, localized dissolution at these minute uncovered areas proceeds several orders of magnitude faster than measured as an average corrosion rate, i.e., it proceeds by a current density expected for Co at $-0.69 \mathrm{~V}$. At this, galvanic potential, Co dissolution proceeds at a catastrophic rate and small exposed areas of the magnetic film disappear completely in minutes. 
Results from the $\mathrm{Cl}_{2}$ exposure test agree well with the deductions from the electrochemical data showing that the coverage by carbon is incomplete. There are numerous sites at which the underlayer is exposed to the corrosive environment. The hillocks of the corrosion products (Co oxide and chloride) are randomly distributed but with a tendency to accumulate along surface scratches or other discontinuities. The average defect count is about 4 $\times 10^{6} / \mathrm{cm}^{2}$ for CoP on the NiP substrate and about $8 \times 10^{4} / \mathrm{cm}^{2}$ for Co on Si. The primary form of corrosion is indeed localized galvanic attack, as is visible from SEM photographs of NiP/CoP and NiP/CoP/C samples after $24 \mathrm{~h}$ exposure (Fig. 7). The uncoated sample has a uniform

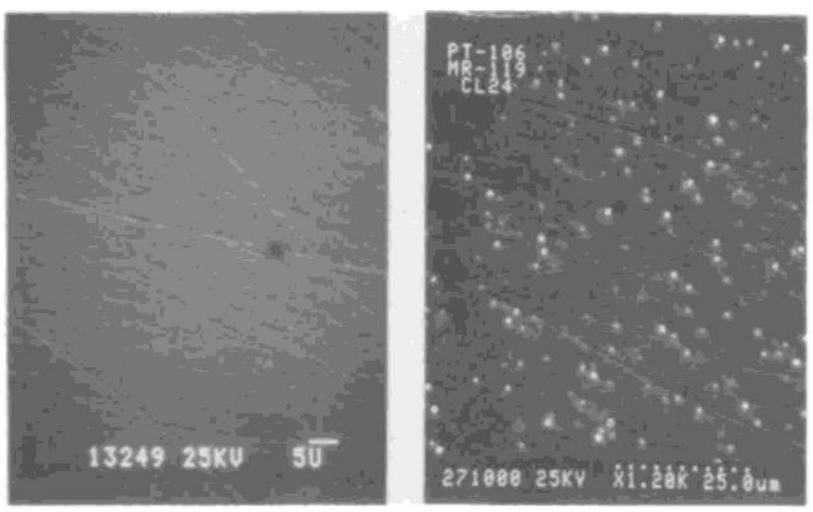

Fig. 7. SEM photograph of $\mathrm{CoP}$ and $\mathrm{CoP} / \mathrm{C}$ surface after $24 \mathrm{~h}$ exposure to $\mathrm{Cl}_{2}$ and $70 \% \mathrm{RH}$ at room temperature (Mag 1200x).

corrosion product, detectable by ellipsometry to be less than $3 \mathrm{~nm}$ thick, while the localized corrosion product on carbon coated samples reached a thickness close to $1 \mathrm{~nm}$ and a diameter of several $\mu \mathrm{m}$ 's.

Reduction of the galvanic mismatch.-A simple way to reduce the galvanic attack between the two layers is to eliminate the electrical contact between them. Table I lists the steady-state values of the corrosion potential and rate on samples of NiP/CoP, NiP/Co, and $\mathrm{Si} / \mathrm{SiO}_{2} / \mathrm{Co}$ covered by a $200 \AA$ thin layer of an amorphous dielectric with and without a carbon overcoat. Again, there is a clear difference between the Si and NiP substrates. The dielectric coating reduced the average corrosion rate by almost three orders of magnitude for Co on Si and by barely $10 \times$ for $\mathrm{Co}$ on $\mathrm{NiP}$. In both cases, if the coverage by the dielectric were full, the corrosion rates would be zero. The results are, thus, a measure of the realistic, if imperfect coverage. As the dielectric layer cannot provide a galvanic action, the corrosion reactions are the same as on the uncoated electrodes and the measured corrosion potentials are unchanged. Furthermore, the measured current is proportional to the area fraction not covered by the dielectric. For $\mathrm{Si} / \mathrm{SiO}_{2} / \mathrm{Co}$, the uncovered area is less than $0.2 \%$, and for Co and $\mathrm{CoP}$ on the $\mathrm{NiP}$ disk substrate, it is about $14.5 \%$ and $55 \%$, respectively. The ratio is proportional to the surface roughening. A relative measure of the surface roughening is obtained by comparing the values of the double layer capacitance. The latter, obtained by ac impedance, is about $12 \mu-\mathrm{F}$ for Co on $\mathrm{Si}$, 23 to $33 \mu \mathrm{F}$ for the $\mathrm{NiP}$ and NiP/Co films, and about 42 to $53 \mu-\mathrm{F}$ for $\mathrm{NiP} / \mathrm{CoP}$ films. The roughness varies on a "macro" scale with defects such as polishing scratches and on a "micro" scale depending on the microstructure of the magnetic layer. The macro roughness is much 
worse for the $\mathrm{AlMg} / \mathrm{NiP}$ substrate than a Si wafer. Microroughening depends on the deposition technique and is worse for plated $\mathrm{CoP}$ as compared to sputter deposited Co.

When the coverage by a dielectric layer is lower, as for NiP/CoP, the use of such a layer to reduce galvanic protection will likely be unsuccessful. The additional layer of carbon, with its own covering ability, will re-establish electrical contact with the magnetic layer and galvanic corrosion will proceed. Thus the presence of a dielectric layer reduces but does not eliminate the galvanic action of the carbon. The average corrosion rates measured on dielectric/ carbon coated samples in DI water are practically the same as on the surfaces covered only by a dielectric. In the more aggressive $\mathrm{Cl}_{2}$ test, however, the carbon coating results in a more aggressive attack. $\mathrm{NiP} / \mathrm{CoP} /$ dielectric samples are not decorated by localized corrosion product while similar samples with a carbon coating show hillocks of Co-chlorides (Fig. 8). On the Si wafer substrate the coverage is better and the dielectric provides the protection expected from the theoretical principles.

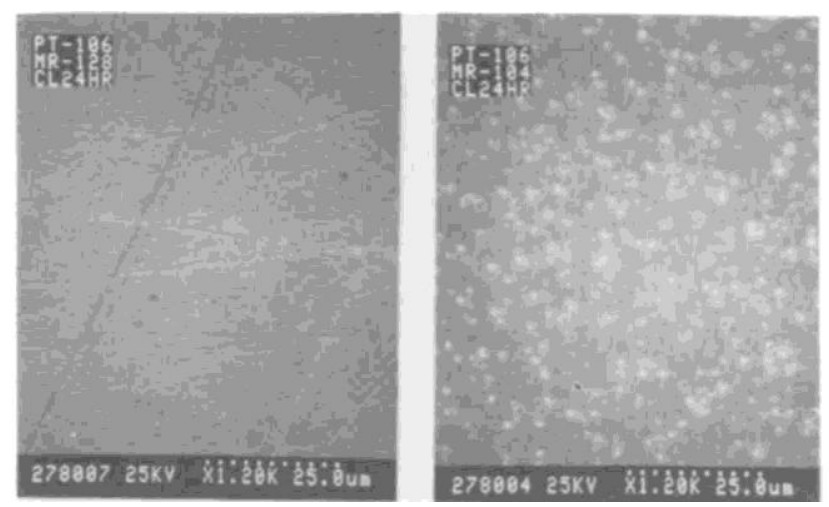

Fig. 8. SEM photograph of CoP/dielectric and CoP/dielectric/carbon surface after $24 \mathrm{~h}$ exposure to $\mathrm{Cl} 2$ and $70 \%$ RH at room temperature (M 1200x).

Another way of reducing the galvanic action in the disk would be to replace the Co or CoP with a more resistant Co-alloy. By comparing the curves in Fig. 5 and 6 it is seen that CoCr, $\mathrm{CoTi}$, and CoNi alloys have higher corrosion potentials which reduces the electromotive force for galvanic corrosion. Similar results have been reported by others (2).

The most effective enhancement of the corrosion resistance of the thin film disk, however, is by elimination of the galvanic activity of the overcoat. A dielectric layer reduces the average disk corrosion proportionally to its coverage without accelerating the dissolution of the uncovered sites.

\section{Conclusions}

1. The principal corrosion form in the thin film disk with carbon coated CoP is the localized dissolution of Co promoted by galvanic interaction with carbon.

2. This galvanic interaction can be reduced by Co-alloying and by the introduction of a dielectric layer between the magnetic film and carbon. The latter approach, however, is of limited success when the films are thin. The best approach to reducing corrosion is to avoid the application of electrochemically active overlayers. 
3. A miniature cell employing filter paper as a carrier of a $20 \mu \mathrm{l}$ volume of water gave the same results as a threeelectrode cell with an unstirred, air saturated bulk electrolyte. It is simple and operable without addition of foreign ionic species to the electrolyte. It mimics the conditions of atmospheric corrosion since electrolytes of low ionic strength can be used and their thinness can bring a lot of oxygen to the surface.

\section{Acknowledgments}

S. M. Rossnagel, J. J. Cuomo, A. Schrott, P. J. Bailey, C. Jahnes, K. Mitchell, J. Baker, G. J. Scilla, C-A. Chang, and W. Freitag contributed to various aspects of the work.

Manuscript submitted Dec. 7, 1987; revised manuscript received May 17, 1988. This was Paper 563 presented at the Honolulu, HI Meeting of the Society, Oct. 18-23, 1987.

IBM Corporation assisted in meeting the publication costs of this article.

\section{REFERENCES}

1. V. Novotny, G. Itnyre, A. Homola, and L. Franco, IEEE Trans. Mag., MAG-23, 3645 (1987).

2. M. Smallen, P. B. Mee, A. Ahmad, and W. Freitag, Paper No. EA-09 presented at Intermag. Conference, St. Paul, MN (1985).

3. Model 350A Corrosion Measurement System, Operating and Service Manual, EG\&G Princeton Applied Research (1980).

4. W. H. Abbott, Battelle Columbus Laboratories, Ninth Progress Report to Environmental Studies Group, unpublished data, p. 58, August 1986.

5. J. O'M. Bockris, A. Despic, and D. Drazic, Electrochim. Acta, 4, 325 (1961).

6. N. Sato and M. Okamoto, This Journal, 111, 897 (1964).

7. M. H. Tikkanen and T. Tuominen, 3rd International Conference on Metallic Corrosion, Moscow, 489 (1966).

8. H. Smyrl, J-B. Ju, Lj. Atansoska, and K. Sandberg, University of Minnesota, Progress Report Nov. 1986.

9. J. O'M. Bockris, M. A. Genshaw, V. Brusic, and H. Wroblowa, Electrochim. Acta, 16, 1859 (1971).

10. M. Pourbaix, "Atlas of Electrochemical Equilibria in Aqueous Solutions," Pergamon Press, Oxford (1966).

11. V. Brusic, J. A. Aboaf, R. D. Maclnnes, and E. I. Alessandrini, Paper 64 presented at The Electrochemical Society Meeting, Minneapolis, MN, May 10-15,1981.

12. R. B. Diegle, C. R. Clayton, M. Hefland, and N. S. Sorensen, Paper presented at NACE meeting, San Francisco, March 11-12,1987. 